\title{
Spanish Lung Cancer Group SCAT trial: surgical audit to lymph node assessment based on IASLC recommendations
}

\author{
José Ramón Jarabo Sarceda ${ }^{1}$, Sergio Bolufer Nadal $^{2}$, Roberto Mongil Poce ${ }^{3}$, Pedro López de Castro ${ }^{4}$, \\ Ramón Moreno Balsalobre ${ }^{5}$, Juan Carlos Peñalver Cuesta ${ }^{6}$, Raul Embún Flor ${ }^{7}$, Joaquín Pac Ferrer ${ }^{8}$, \\ Francisco Javier Algar Algar', Antonio Pablo Gámez García ${ }^{10}$, Marcelo F. Jiménez ${ }^{11}$, \\ Jesús Gabriel Sales-Badía ${ }^{12}$, Eva Pereira ${ }^{13}$, Bartomeu Massuti ${ }^{14}$, Mariano Provencio ${ }^{15}$, \\ Florentino Hernando Trancho ${ }^{1}$
}

${ }^{1}$ Department of Thoracic Surgery, Hospital Clínico San Carlos, Madrid, Spain; ${ }^{2}$ Department of Thoracic Surgery, Hospital Universitario de Alicante, Alicante, Spain; ${ }^{3}$ Department of Thoracic Surgery, Hospital Universitario de Málaga, Málaga, Spain; ${ }^{4}$ Department of Thoracic Surgery, Hospital Universitari Germans Trias i Pujol, Barcelona, Spain; ${ }^{5}$ Department of Thoracic Surgery, Hospital Universitario de la Princesa, Madrid, Spain; ${ }^{6}$ Department of Thoracic Surgery, Instituto Valenciano de Oncología, Valencia, Spain; ${ }^{7}$ Department of Thoracic Surgery, Hospital Universitario Miguel de Servet, IIS Aragón, Zaragoza, Spain; ${ }^{8}$ Department of Thoracic Surgery, Hospital Universitario de Cruces, Bilbao, Spain; ${ }^{9}$ Department of Thoracic Surgery, Hospital Universitario Reina Sofía de Córdoba, Córdoba, Spain; ${ }^{10}$ Department of Thoracic Surgery, Hospital Universitario 12 de Octubre, Madrid, Spain; ${ }^{11}$ Department of Thoracic Surgery, Hospital Universitario de Salamanca, Salamanca, Spain; ${ }^{12}$ Department of Thoracic Surgery, Hospital Universitario la Fe, Valencia, Spain; ${ }^{13}$ Spanish Lung Cancer Group, Barcelona, Spain; ${ }^{14}$ Department of Medical Oncology, Hospital Universitario de Alicante, Alicante, Spain; ${ }^{15}$ Department of Oncology, Hospital Universitario Puerta de Hierro Majadahonda, Madrid, Spain

Contributions: (I) Conception and design: JR Jarabo Sarceda, F Hernando Trancho; (II) Administrative support: E Pereira, B Massuti, M Provencio; (III) Provision of study materials or patients: All authors; (IV) Collection and assembly of data: JR Jarabo Sarceda, E Pereira; (V) Data analysis and interpretation: JR Jarabo Sarceda, E Pereira, F Hernando Trancho; (VI) Manuscript writing: All authors; (VII) Final approval of manuscript: All authors.

Correspondence to: José Ramón Jarabo Sarceda, MD, PhD. Hospital Clínico San Carlos, Calle Profesor Martín Lagos s/n, 28040 Madrid, Spain.

Email: jrjarabo@hotmail.com.

Background: The Spanish Customized Adjuvant Therapy (SCAT) trial assessed the role of individualized adjuvant therapy in clinical N0 incidental pN1 and/or N2 non-small cell lung cancer (NSCLC) completely resected. We assessed surgical topics with an in-depth analysis of quality of lymphadenectomy based on International Association for the Study of Lung Cancer (IASLC) recommendations.

Methods: Patients with information about lymphadenectomy available were included (N=451). Prospectively collected data about tumor, type of resection, and postoperative morbidity and quality of lymph node dissection (LND) were retrospectively evaluated. Role of lymph node assessment on survival was analyzed using Kaplan-Meier curves, using regression models to identify prognostic factors.

Results: In $33.7 \%, 17.7 \%$ and $49.9 \%$ of cases, regions 7, 10 and 11 respectively were not assessed. In $21.1 \%$ of patients, less than three lymph node regions were biopsied, while in $19.6 \%$ of patients less than six lymph nodes were assessed. In 53,4\% of patients only one N1 region was evaluated. From patients with positive N2, 8.9\% had no N1 regions biopsied. Twenty-nine percent of patients with at least one N2 lymph node resected shown the highest region involved. Thirty-day postoperative mortality was unknown. Fiveyear overall survival (OS) was 61.7\% (95\% CI: 55.4-67.4\%), 51.5\% (95\% CI: 39.2-62.4\%) and 42.3\% (95\% CI: $32.1-52.2 \%)$ for patients with $\mathrm{N} 1, \mathrm{~N} 2$ and $\mathrm{N} 1+\mathrm{N} 2$ disease, respectively $(\mathrm{P}<0.01)$. Both number of lymph nodes resected and number of lymph nodes involved by tumor were significantly related to prognosis.

Conclusions: IASLC recommendations for surgical resections were not followed in a high proportion of surgical procedures. Hilar and mediastinal lymph node assessment and involvement showed to impact prognosis. Surgical issues such as postoperative mortality could not be evaluated owing to trial design. 
Keywords: Non-small cell lung cancer (NSCLC); surgery; lymph node dissection (LND); survival

Submitted Sep 19, 2020. Accepted for publication Feb 26, 2021.

doi: $10.21037 /$ tlcr-20-1055

View this article at: http://dx.doi.org/10.21037/tlcr-20-1055

\section{Introduction}

Surgical resection is the standard treatment with curative purpose for early stage non-small cell lung cancer (NSCLC). However, published 5 -year survival rates following complete resection (CR) range between $63 \%$ in stage IA and $19 \%$ in stage IIIA (1). Chemotherapy (ChT) and/or radiation (RT) are added to improve survival for patients with operable NSCLC. Adjuvant ChT seems to offer an overall absolute benefit of 4-5\% (2-4). The Spanish Lung Cancer Group (SLCG) developed the Spanish Customized Adjuvant Therapy (SCAT) trial, a multicenter trial in which 500 completely resected p-stage II-IIIA NSCLC patients were randomized to receive standard adjuvant ChT or, in the experimental arm, three different therapeutic schemes based on levels of tumor BRCA1 expression (SLCG-SCAT trial) (5).

CR is a common inclusion condition in most trials analyzing adjuvant treatment. The International Association for the Study of Lung Cancer (IASLC) proposed in 2005 a definition of CR for NSCLC (6). Systematic nodal dissection (ND) or lobe-specific nodal dissection (LSND) are widely recommended, the latter implying dissection and histological examination of intrapulmonary (regions 11 and following) and hilar (region 10) nodes and at least, three N2 regions depending on lobar location of the primary tumor. Analysis of regions 7 and 10 is mandatory regardless tumor location. Minimal number of resected lymph nodes is 3 from $\mathrm{N} 1$ and $\mathrm{N} 2$ regions.

In this study we performed a surgical audit of patients from the SLCG-SCAT trial database. Our main objective was the assessment of CR criteria, with an in-depth analysis of quality of lymphadenectomy. We also analyzed the pattern of tumor lymphatic widespread according to location and histologic subtype, and the prognostic role of different patterns of hilar and mediastinal involvement.

We present the following article in accordance with the STROBE reporting checklist (available at: http://dx.doi. org/10.21037/tlcr-20-1055).

\section{Methods}

SCAT-SLCG trial consisted of a phase III multicenter prospective randomized trial including patients with $\mathrm{CR}$ of clinical N0 NSCLC with incidental pathological hilar and/ or ipsilateral mediastinal lymph node involvement (pN1/ pN2). Patients were operated on between July 2007 and May 2013. Additional inclusion criteria included: Karnofsky index $(\mathrm{KI})>70$, completely recovered from surgery within 6 weeks, no prior RT or ChT, age $>18$ years and signed informed consent. Previous oncological disease within five years before surgery or neoadjuvant ChT and/or RT were exclusion criteria. Patients were randomized into two groups: patients in the control arm received adjuvant treatment with docetaxel-cisplatin while those in the experimental arm received gemcitabine-cisplatin, docetaxelcisplatin or docetaxel depending on tumor BRCA1 expression level. Stratification factors were N1 vs. N2, histology (squamous/non-squamous), extent of resection (lobectomy vs. pneumonectomy) and BRCA1 levels and quartile distribution. Primary endpoint was disease-free survival (DFS). Secondary endpoints were survival, toxicity profiles and recurrence pattern. Statistical hypothesis: randomization 1:3 (control/experimental arms); accrual: 432 patients; 5 -year survival rate $45 \%$ for the control group, with an absolute improvement of $20 \%$ in the experimental group; $80 \%$ powered; two-sided type I error of $5 \%$; and anticipated loss of $10 \%$ cases.

Patients from SLCG-SCAT trial in whom a complete pathologic report with information about hilar and mediastinal lymph node dissection (LND) was available were included for our study. We retrospectively analyzed information prospectively collected on the tumor (location, stage, histological classification), type of resection, and postoperative morbidity and mortality (30 and 90 days), and collected a large amount of data related to LND (including number of lymph nodes assessed and involved by tumor in each intrapulmonary, hilar and mediastinal region). For the design of database, surgeons from the SLCG actively 
Table 1 Anatomic and pathological data of the whole series

\begin{tabular}{|c|c|}
\hline Variables & Number, n (\%) \\
\hline Total & $451(100.0)$ \\
\hline \multicolumn{2}{|l|}{ Type of resection } \\
\hline Lobectomy & $310(68.7)$ \\
\hline Bilobectomy & $21(4.7)$ \\
\hline Left pneumonectomy & $83(18.4)$ \\
\hline Right pneumonectomy & $32(7.1)$ \\
\hline Wedge resection & $1(0.2)$ \\
\hline Segmentectomy & $4(0.9)$ \\
\hline \multicolumn{2}{|l|}{ Primary tumor location } \\
\hline Left lower lobe & $78(17.3)$ \\
\hline Left upper lobe & $153(33.9)$ \\
\hline Involving both left lobes & $5(1.1)$ \\
\hline Right lower lobe & $59(13.1)$ \\
\hline Medium lobe & $16(3.5)$ \\
\hline Right upper lobe & $126(27.9)$ \\
\hline Right medium and lower lobes & $9(2.0)$ \\
\hline Right medium and upper lobes & $2(0.4)$ \\
\hline Right hilum & $1(0.2)$ \\
\hline Non specified & $2(0.4)$ \\
\hline \multicolumn{2}{|l|}{ Histology } \\
\hline Adenocarcinoma & $223(49.5)$ \\
\hline Squamous carcinoma & 198 (43.9) \\
\hline Undifferentiated NSCLC & $23(5.1)$ \\
\hline Adenosquamous & $4(0.9)$ \\
\hline Pleomorfic carcinoma & $3(0.7)$ \\
\hline \multicolumn{2}{|l|}{ TNM classification ( $6^{\text {th }}$ edition) } \\
\hline T1N1M0 & $51(11.3)$ \\
\hline T1N2M0 & $38(8.4)$ \\
\hline T2N1M0 & $174(38.6)$ \\
\hline $\mathrm{T} 2 \mathrm{~N} 2 \mathrm{MO}$ & $118(26.2)$ \\
\hline T3N1M0 & $47(10.4)$ \\
\hline T3N2M0 & $23(5.1)$ \\
\hline \multicolumn{2}{|l|}{ Stage } \\
\hline$\| \mathrm{A}$ & $51(11.3)$ \\
\hline IIB & $174(38.6)$ \\
\hline IIIA & $226(50.1)$ \\
\hline
\end{tabular}

NSCLC, non-small cell lung cancer. participated, in order to standardize terminology and variables amenable to be analyzed. IASLC hilar and mediastinal classification was used to properly name lymph node regions.

\section{Statistical analysis}

Student $t$-test was used to compare independent means. Finally, we analyzed estimated overall survival (OS) and DFS from date of surgery using Kaplan-Meier curves. Multiple comparisons of survival curves were performed using Benjamini-Hochberg-Yekutieli correction. Univariate analysis to identify survival-related factors was performed using Cox regression test. All patients underwent surgical resection in high-volume departments of thoracic surgery by surgeons with expertise in oncological procedures.

\section{Ethical statement}

The study was conducted in accordance with the Declaration of Helsinki (as revised in 2013). The study was approved by institutional/regional/national ethics/ committee/ethics board of every hospital participating in the trial (2007-000067-15) and informed consent was taken from all the patients.

\section{Results}

\section{Lymph node assessment}

A total of 500 patients were included in the SLCG-SCAT trial. Complete pathologic report was available in 451 $(90.2 \%)$ of the whole series. Anatomic and pathological data are summarized in Table 1. Table 2 provides information on the analysis and involvement of lymph nodes from different regions (level 1 to 14). On the whole series, in $33.7 \%$ of cases region 7 was not assessed, while in $17.7 \%$ region 10 was not evaluated. Only $3.5 \%$ of patients had no N1 regions biopsied. However, interlobar region (number 11) was not evaluated in $49.9 \%$ of patients.

As we can see in Tables S1,S2, in $19.6 \%$ of patients less than six lymph nodes were assessed, tearing up one of the main criteria of quality of LND. Mean number of mediastinal regions assessed was 3.82 (range, 1 to 10 ). In $21.1 \%$ of patients, lymph nodes from only one or two regions were obtained.

When we analyzed separately $\mathrm{N} 1$ and $\mathrm{N} 2$ regions, we found that in $53.4 \%$ of patients only one $\mathrm{N} 1$ region was assessed. The mean number of N1 lymph nodes analyzed was 5.78 , with a median of 5 (range, $0-24$ ). 
Table 2 Number of lymph node regions and lymph nodes resected and involved from hilar and mediastinal regions 1 to 14

\begin{tabular}{|c|c|c|c|c|c|c|c|c|c|c|c|c|c|c|}
\hline Variables & \multicolumn{14}{|c|}{ LN region } \\
\hline No LN resected (NP) & 440 & 404 & 406 & 282 & 271 & 393 & 152 & 361 & 279 & 80 & 225 & 411 & 438 & 450 \\
\hline At least one LN resected (NP) & 11 & 47 & 45 & 169 & 180 & 58 & 299 & 90 & 172 & 371 & 226 & 40 & 13 & 1 \\
\hline Absolute number of LN resected & 23 & 152 & 113 & 581 & 489 & 107 & 887 & 140 & 257 & 1,720 & 675 & 177 & 33 & 1 \\
\hline \multicolumn{15}{|l|}{ Number of LN involved } \\
\hline 0 & 7 & 37 & 32 & 119 & 126 & 51 & 235 & 83 & 157 & 93 & 116 & 14 & 6 & 1 \\
\hline 1 & 3 & 6 & 10 & 30 & 37 & 6 & 40 & 5 & 15 & 159 & 71 & 17 & 6 & 0 \\
\hline 2 & 0 & 2 & 1 & 9 & 8 & 1 & 13 & 1 & 0 & 67 & 23 & 5 & 1 & 0 \\
\hline Involved LN/resected LN (\%) & 30.4 & 11.2 & 16.8 & 16.5 & 17.6 & 7.5 & 13.0 & 8.6 & 5.8 & 27.9 & 26.7 & 29.4 & 24.2 & 0.0 \\
\hline
\end{tabular}

LN, lymph node/s; NP, number of patients.

Regarding N2 regions, a median of 2 stations were analyzed (range, 0 to 7 ). In 42 patients $(9.3 \%)$ no $\mathrm{N} 2$ regions were assessed. In $47.9 \%$ of patients, at least three $\mathrm{N} 2$ regions were biopsied, which is a mandatory IASLC criterion for considering CR. A median of five N2 lymph nodes were resected (range, $0-28$ ).

In terms of tumor-positive regions and lymph nodes, we found that 304 patients $(67.4 \%)$ had one station involved, and 203 patients (45\%) had only one lymph node affected. A total of 272 patients $(60.3 \%)$ had only N1 disease, while 75 patients $(16.6 \%)$ presented only $\mathrm{N} 2$ involvement (skip metastases). However, 16 patients without N1 regions assessed had N2 involvement (i.e., 21\% of patients considered as having skip metastases had no N1 regions evaluated). When reviewing 179 patients with N2 involvement, we found that $16(8.9 \%)$ had no N1 regions biopsied, 98 (54.7\%) had only one and $65(36.4 \%)$ had two or more regions analyzed.

Of 272 patients with N1 disease only, 246 (90.4\%) had only one N1 region affected. Furthermore, of 75 patients with $\mathrm{N} 2$ involvement only, 58 (77.3\%) presented singlestation disease. We also found that of 409 patients with any N2 lymph node resected, N2 was the highest region involved in 120 (29.3\%) of them.

The absolute number of lymph nodes resected was higher among patients undergoing pneumonectomy than in those undergoing lobectomies or bilobectomy (mean 13 vs. 11.5 lymph nodes, $\mathrm{P}=0.03$ ). Likewise, both the number of regions and lymph nodes affected were higher for adenocarcinomas $(\mathrm{P}<0.05)$.

No differences were found regarding type of resection, histology and T-stage between patients with only N1, only $\mathrm{N} 2$ and $\mathrm{N} 1+\mathrm{N} 2$ disease. However, both the number of mediastinal regions assessed and affected, and the number of lymph nodes resected and affected were significantly higher in patients with $\mathrm{N} 1+\mathrm{N} 2$ disease than those with solely N1 or N2 involvement. Moreover, the more number of lymph nodes assessed, the higher rate of $\mathrm{N} 1+\mathrm{N} 2$ disease.

Next, we analyzed distribution of mediastinal regions assessed and involved regarding location of primary tumor (Tables S1,S2). We found different patterns of lymph nodes dissection. For example, for tumors in the right upper lobe ( $\mathrm{n}=126$ ), we found that regions $2 \mathrm{R}, 4 \mathrm{R}, 7$ and $11 \mathrm{R}$ were assessed in $20.6 \%, 69.9 \%, 67.5 \%$ and $47.6 \%$ of patients, respectively. Similarly, for tumors located in the left lower lobe $(\mathrm{n}=78)$, at least one lymph node from regions 5, 6, 7 and $10 \mathrm{~L}$ was resected in $14.1 \%, 23.1 \%, 65.4 \%$ and $80.8 \%$ of patients, respectively. The pattern of lymph node region involvement regarding the location of primary tumor offers useful information about unsteady loco-regional spread of lung cancer.

\section{Surgical morbidity and mortality}

Morbidity rate was $27.7 \%$ (125 patients), being air leak 
(5.1\%) and arrhythmias (3.8\%), the complications most frequently described. Given that mortality within six weeks after surgery was an exclusion criterion, we do not have 30 -day mortality rate. However, the 42 - to 90 -day mortality rate was $1.8 \%$ ( 8 patients, 3 of them due to sudden death).

\section{OS}

Median follow-up was 52.3 months. A total of 212 patients (47\%) died during the follow-up. Figure 1 shows the OS curves for the whole series (Figure $1 A$ ) and divided according to N1 and/or N2 involvement (Figure 1B). Median OS was 79.3 months (95\% CI: 63.7-106.4 months). Two-year OS was 76.7\% (95\% CI: 72.4-80.3\%). Five-year OS was $55.7 \%$ (95\% CI: 50.8-60.3\%). Differences were found in OS regarding type of lymph node involvement (N1, N2 or both). When analyzing these groups in pairs, differences were found only between $\mathrm{N} 1+\mathrm{N} 2$ involvement and N1 disease only. The outcome of patients with skip metastases was similar to those with $\mathrm{N} 1$ and $\mathrm{N} 2$ disease. Median survival was 42.7 and 65.2 months for patients with $\mathrm{N} 1+\mathrm{N} 2$ and N2 only disease, respectively. Median was not reached among patients with only N1 involvement. Fiveyear OS for the three groups was $61.7 \%$ (95\% CI: $55.4-$ $67.4 \%$ ), $51.5 \%$ (95\% CI: $39.2-62.4 \%$ ) and $42.3 \%$ (95\% CI: $32.1-52.2 \%)$ for patients with $\mathrm{N} 1, \mathrm{~N} 2$ and $\mathrm{N} 1+\mathrm{N} 2$ disease, respectively $(\mathrm{P}=0.02)$. Among patients with one or more N2 regions biopsied, no differences were found in survival in terms of the total number of $\mathrm{N} 2$ regions evaluated $(\mathrm{P}=0.97)$. Similarly, among patients with at least one N1 regions biopsied, number of regions did not affect OS $(\mathrm{P}=0.25)$. Table 3 shows the univariate model using Cox regression to evaluate the impact of pathological factors on OS. The number of mediastinal regions assessed did not affect OS. Patients with more than eight lymph nodes resected showed significant better overall survival $(\mathrm{P}=0.03)$. Both the number of regions involved and the number of tumor-positive lymph nodes were significantly related to a worse prognosis. Likewise, multistation N2 disease indicated a poor prognosis, with a hazard ratio (HR) of 2.16 (1.41-3.32: $\mathrm{P}<0.001)$. Type of resection did not appear to affect prognosis. Histology other than adenocarcinoma and squamous disease (30 cases) had a better prognosis $(\mathrm{P}=0.03)$.

\section{DFS}

Median DFS was 36.6 months (95\% CI: 26.7-45.8). Two- and five-year DFS was $58.1 \%$ (95\% CI: $53.3-62.5 \%$ ) and $41.3 \%$ (95\% CI: 36.6-45.8\%), respectively. During the follow-up, 222 patients (49.2\%) experienced disease relapse, being lung, lymph nodes and bone the most frequent foci of progression. In 148 cases (66.7\%) progression involved a single site. No major differences were found in the pattern of progression regarding lymph node involvement. However, tumors with only N1 involvement showed significantly higher lymph node progression than those with only $\mathrm{N} 2$ or $\mathrm{N} 1+\mathrm{N} 2$ disease.

Figure 2 shows DFS curves for the whole series (Figure $2 A$ ) and for the three groups with N1, N2 and $\mathrm{N} 1+\mathrm{N} 2$ disease (Figure 2B). As in OS, significant differences were found between patients with $\mathrm{N} 1+\mathrm{N} 2$ disease and those with N1 involvement only. No significant differences were found in other comparisons between groups. Median DFS was 44.6, 38.1 and 24.7 months for patients with N1, $\mathrm{N} 2$ and $\mathrm{N} 1+\mathrm{N} 2$ disease, respectively. Five-year DFS was $45.8 \%$ (95\% CI: $39.7-51.6 \%$ ) for N1, $40.1 \%$ (95\% CI: $28.8-51.1 \%$ ) for $\mathrm{N} 2$ and $30 \%$ (95\% CI: $21.2-39.3 \%$ ) for $\mathrm{N} 1+\mathrm{N} 2$.

Table 4 shows the univariate model using Cox regression to evaluate the impact of pathological factors on DFS. Number of mediastinal regions assessed did not affect OS. The number of lymph nodes resected was significantly associated with worse DFS ( $\mathrm{P}=0.018)$. Again three or more regions involved and three or more lymph nodes with tumor associated worse prognosis in terms of DFS. Again, multistation $\mathrm{N} 2$ was associated with worse DFS, with an HR of 1.65 (1.41-2.46; $\mathrm{P}=0.013)$. Pneumonectomy was associated with better DFS rates with an HR of $0.38(0.20$ $0.72 ; \mathrm{P}=0.002)$. Finally, squamous cell carcinoma and other histological subtypes had worse prognosis in terms of DFS compared to adenocarcinoma $(\mathrm{P}=0.02)$.

\section{Discussion}

Surgery still remains the most effective treatment with curative purpose for early-stage (IA-IIB) and selected cases of stage III NSCLC. Adjuvant therapy attempts to eradicate the remaining cancer cells in a subset of resected patients in order to achieve cure in a higher number of cases. However, it is difficult to predict who will benefit from adjuvant treatment.

Careful pathological staging is mandatory to better predict prognosis, facilitate patient selection for adjuvant regimen, avoid biases and permit proper comparisons of treatment outcomes among trials (7). 
Table 3 Overall survival according to anatomic and pathological characteristics

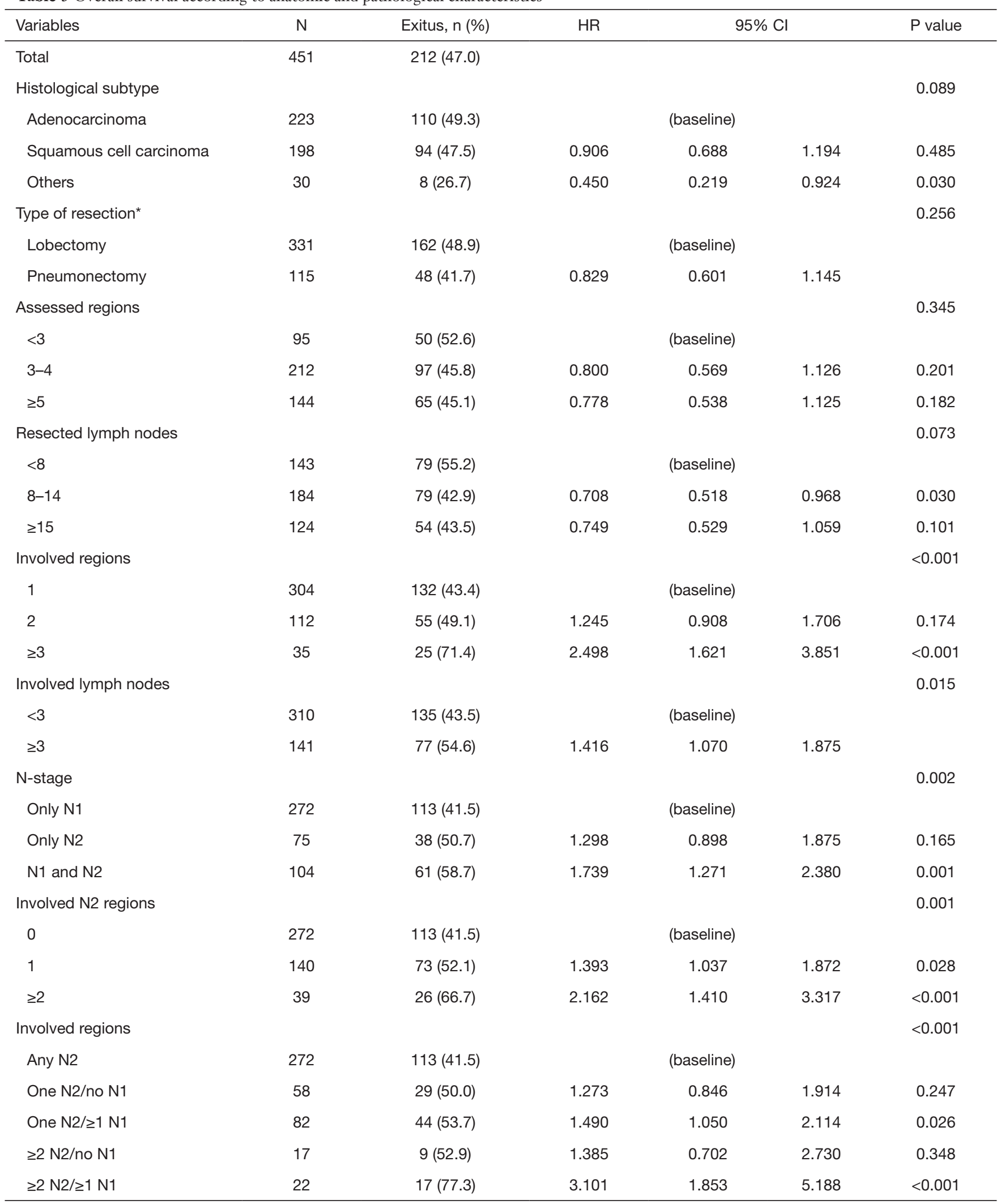

*, 5 missed cases were sublobar resections. HR, hazard ratio. 

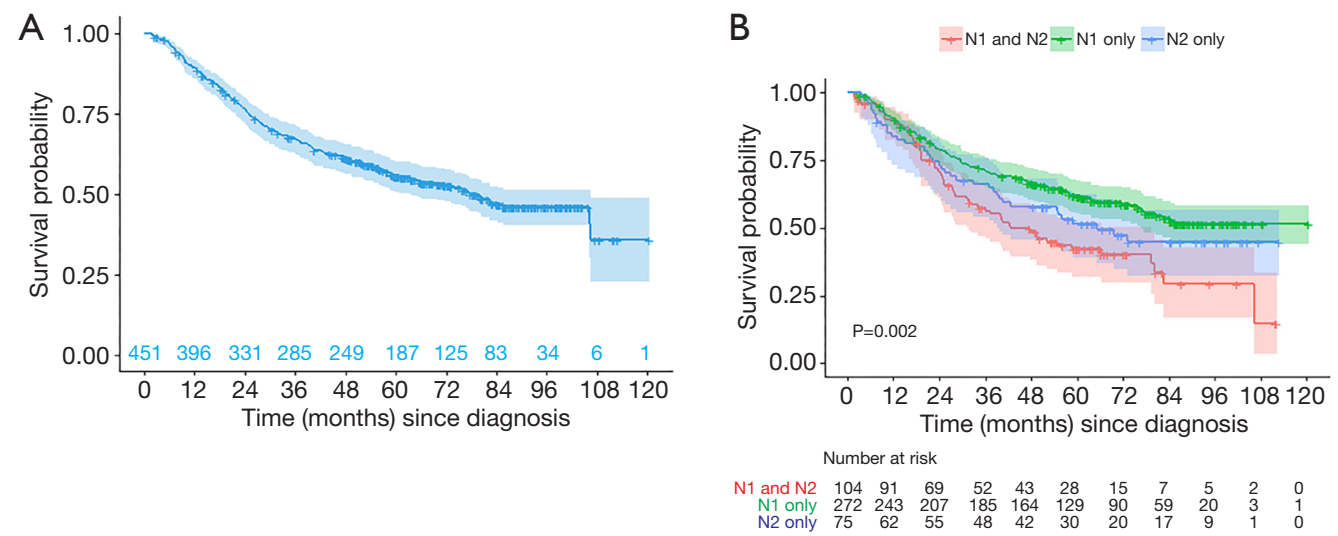

Figure 1 Overall survival. (A) Whole series. (B) Classified by hilar/mediastinal lymph node involvement.
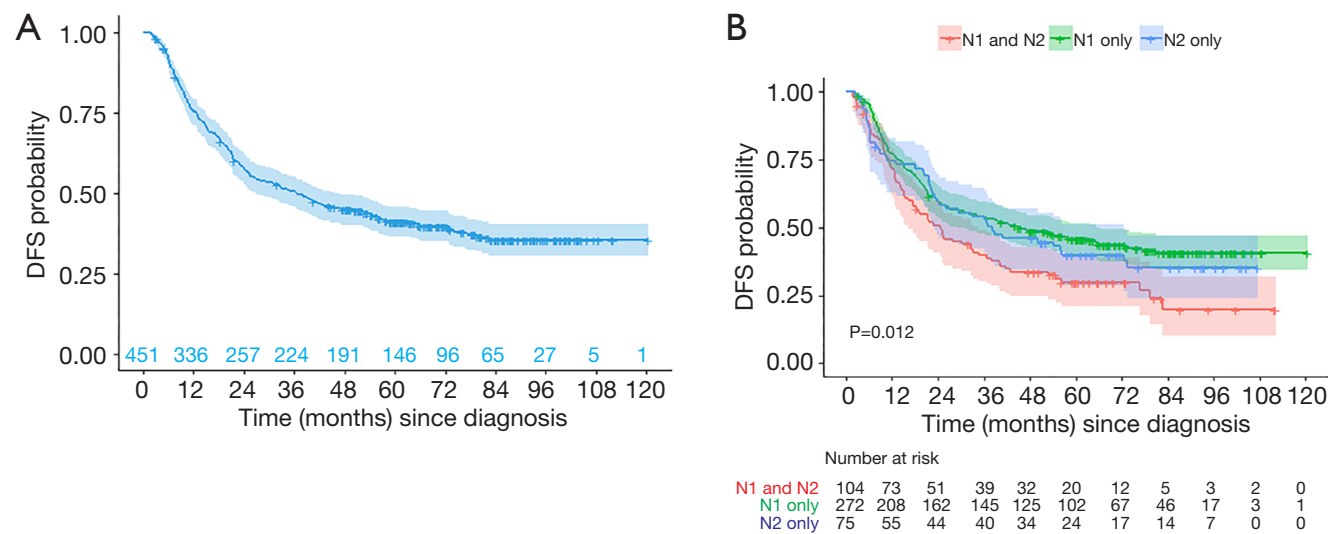

Figure 2 Disease-free survival (DFS). (A) Whole series. (B) Classified by hilar/mediastinal lymph node involvement.

The standard surgical approach to resectable earlystage NSCLC is anatomical resection and mediastinal LND. Types of anatomic resection (typical segmentectomy, lobectomy, bilobectomy or pneumonectomy) are well defined. However, the approach to mediastinal surgical staging is rarely established when designing trials.

Most important randomized studies evaluating the role of ChT in surgical series are imprecise when defining eligibility criteria with respect to mediastinal $\operatorname{LND}(2,4,8,9)$.

The next two steps in the evaluation of the role of adjuvant ChT were the selection of the subset of patients who may benefit more, and the selection of targeted therapies according to patient and tumor characteristics. In this respect, the SLCG developed the SCAT Ph III trial, assessing the role of adjuvant ChT based on BRCA1 levels in NSCLC node-positive resected patients, under the hypothesis that analysis of the expression of the genes involved in DNA repair could be used to individualize optimal ChT drugs and regimens. Patients undergoing R0 major resection (lobectomy/pneumonectomy) of NSCLC with pathological N1 and/or N2 nodal status were included. Detailed information regarding the surgical lymph node approach was available in $90.2 \%$ of patients. Insufficient data was available for 49 patients included for the analysis of the main trial endpoint (targeted adjuvant treatment regimens). The first idea to bear in mind is that the trial analyzed a cohort of patients with preoperative unsuspected pathological $\mathrm{N}$ disease in which LND demonstrated this involvement. Homogeneous algorithms of preoperatory mediastinal staging were not mandatory for the inclusion of patients. Thus, some patients included could have not been properly staged preoperatively so that they could be amenable to received neoadjuvant treatment. The ability of surgeons to identify $\mathrm{N}$ disease among patients with clinical N0 NSCLC cannot be evaluated here. LND among patients of our series had enough quality to detect $\mathrm{N}$ 
Table 4 Disease free survival regarding anatomic and pathological issues. Cox univariate analysis

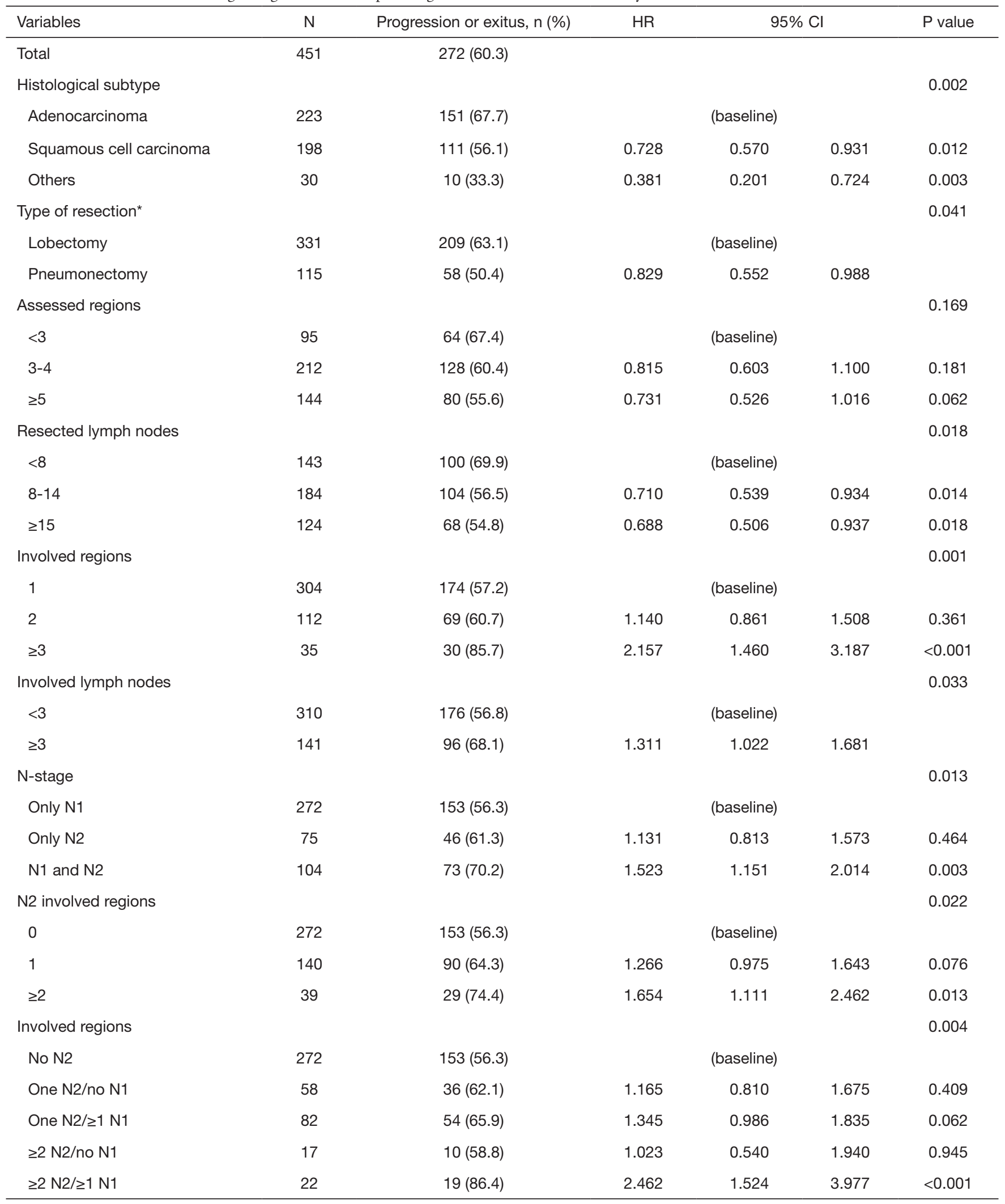

*, 5 missed cases were sublobar resections. HR, hazard ratio. 
disease.

The IASLC has established minimum recommendations regarding surgical evaluation of lymph node involvement in NSCL (6). Rates of attainment of these recommendations define nodal staging quality. Analysis of large databases from different countries and groups are discouraging: 50\% of resections for NSCLC did not include N2 lymph nodes $(10,11)$. Up to nearly $20 \%$ failed to examine any lymph node (12). Up to $20 \%$ showed no N1 regions assessed (13) and $\mathrm{pN} 0$ patients did not accomplish the minimum criteria for mediastinal assessment (14). In our series, if we focus on lymph node stations whose evaluation is fully recommended, we find that $33.7 \%$ and $17.7 \%$ of regions 7 and 10 respectively, were not assessed. Furthermore, 15.4\% of patients with $\mathrm{N} 1$ involvement only had no $\mathrm{N} 2$ regions biopsied, and $20.2 \%$ had only one N2 region evaluated. Finally, in less than half of the patients three or more N2 regions were assessed, as recommended.

The role of surgical mediastinal lymph node assessment has been widely analyzed in early-stage NSCLC. Data suggest that the higher the number of lymph nodes evaluated, the better the survival outcomes (15). However, among patients with hilar and/or mediastinal pathologic lymph node involvement, the focus moves to the role of adjuvant therapies, regardless of the extension of lymph node disease. Beyond N1 (stage II) or N2 (stage IIIA) disease, further classifications have been proposed for pathological N-positive NSCLC. Legras et al. [2014] analyzed patients with NSCLC undergoing curative resection with complete mediastinal LND in two French centers over 29 years. Among pN2 patients, the combination of N1 involvement and number of involved N2 stations were independent prognostic factors (16). Zheng et al. [2011] reappraised N2 disease and found differences in survival regarding lymphatic drainage pattern (17). Finally, Yoo et al. [2015] found that the number of pathologic lymph nodes involved was an independent prognostic factor for OS and DFS among patients with IIIA-N2 NSCLC undergoing CR (18). In our series, survival differences were found when comparing $\mathrm{N} 1$ versus $\mathrm{N} 1+\mathrm{N} 2$ disease. The role of the type of LND as a confounding factor should be assessed in clinical trials evaluating outcomes of patients undergoing surgery for NSCLC. In this respect, Smeltzer et al. [2018] analyzed more than two thousand patients undergoing surgical resection for NSCLC and detected different patterns of LND, demonstrating that the prognostic value of $\mathrm{pN}$ stratification depends on the thoroughness of examination (19). The authors recommended that future updates of TNM staging system should include more quality restraints.

The role of skip metastases (i.e., N2 involvement without N1 disease) has also been widely analyzed. Yazgan et al. [2018] found similar survival rates among patients with N1 disease and single-station N2 disease without $\mathrm{N} 1$ involvement (20). The analysis of information from the IASLC database led it to recommend the recording of the number of metastatic lymph nodes (or stations) and to further classify the $\mathrm{N}$ category using a new proposal of $\mathrm{N} 1$ and N2 sub-classification (21). Even the examination of regions 13 and 14 (only available in the surgical specimen) seems to play a role in better selection of $\mathrm{N}$-positive patients and probably in survival itself (22). In our series, 75 patients $(16.6 \%)$ were presented as having only N2 involvement. However, when analyzed in detail, 16 of these patients we could consider having skip metastases (21\%) had no N1 regions evaluated. Furthermore, when reviewing 179 patients with $\mathrm{N} 2$ involvement, we found that $16(8.9 \%)$ had no N1 regions biopsied, 98 (54.7\%) had only one and 65 (36.4\%) had two or more regions analyzed. Thus, we consider that N1 lymph node assessment in particular was suboptimal in our study. Interlobar region is the most proximal station that is usually biopsied separately from the surgical specimen when the surgeon performs a lobectomy. Stations 12 to 14 are intrapulmonary, so they are completely resected with the lobe, being frequently identified by the pathologist in the lab. Therefore, lymph nodes from region 11 are sometimes considered a type of sentinel node. Moreover, for many authors, assessment of region 11 and detection of lymph node involvement at this level could even explain the better results of lobectomy over sublobar resections (23). In our series, in nearly half of the patients $(49.8 \%)$ region 11 was not assessed.

As we have seen, another IASLC requirement for a surgical CR is the absence of tumor in the highest resected lymph node (6). Moreover, IASLC recommends the isolation and specific labelling of the highest resected lymph node. Despite this is a factor usually overlooked when analyzing survival in resected NSCLC, it has been properly validated (24). In our series, nearly $30 \%$ of 409 patients with any N2 lymph node resected showed involvement of the highest region removed.

In our univariate model, the number of mediastinal regions evaluated did not affect OS. The number of resected lymph nodes was associated with a better prognosis but did not reach statistical significance. The number of regions and lymph nodes involved was associated with 
lower OS rates. Combined N1-positive and one N2 region affected had an HR of $1.49(\mathrm{P}=0.026)$. The HR for $\mathrm{N} 1$ and more than one mediastinal region affected increased to 3.101 $(\mathrm{P}<0.001)$. However, in our series, N2 involvement with negative N1 (skip metastases) did not affect OS. A major limitation of this finding is the aforementioned rate of "false-skip metastases". Furthermore, our cohort of patients is different from most studies analyzing mediastinal LND, provided that $\mathrm{pN} 0$ patients are usually included, being in many cases the target of those studies.

In our series mediastinal regions examined for location of the primary tumor did not follow international recommendations with respect to lobe-specific mediastinal LND. The heterogeneous pattern of disease spread found in our study is consistent with that of Liang et al. [2018] showing that, among $\mathrm{pN} 2$ patients, each mediastinal region can be involved in more than $5 \%$ of cases, and advocating systematic mediastinal LND as the preferred procedure for surgical mediastinal evaluation (25).

Two frequently underestimated cornerstones when defining lymph node regions are surgical and pathological issues. A well-defined and widely accepted mediastinal lymphatic map is based on radiological static anatomic landmarks. Boundaries in the surgical field are not so precise, provided that tissue mobilization during dissection shifts lymph nodes. Moreover, mediastinal tissue extends as a continuous network without well-defined boundaries. With respect to the pathological approach, no universal criteria for measuring the quality of lymph node examination quality are available. Management and labeling of samples are not always standardized. Interventions aimed at surgical and pathology teams have proven to improve the quality of nodal staging of NSCLC (26). Interesting findings in our series are those related to $\mathrm{N} 1$ evaluation. The highest number of lymph nodes obtained was from region 10 (median 4.64). Anatomic landmarks in this region are limited. The gap between region 11 and region $4 \mathrm{R}$ (right side) and 5 (left side) in which 10 lymph nodes are located is, in the surgeon's eyes, quite small (when compared to other N1 and N2 regions). Another noteworthy finding is that region 12 was only assessed (usually once the specimen had been excised) in $9 \%$ of resections. However, a mean of 4.4 lymph nodes were separated and almost $30 \%$ of them were positive, suggesting that the more accurately the specimen is managed, the more information that may be obtained. Even sublobar node collection (regions 13 and 14) has been proven to be a prognostic factor for completely resected pN0 cases (22).
Another major limitation when analyzing a surgical series is the fact that postoperative mortality cannot be evaluated. Only patients with a good clinical status and having properly completed adjuvant treatment after six weeks were included. Even for surgical series, the trial design usually focuses on oncological aspects more than surgical issues that could work as confounding factors when evaluating outcomes. In our series, rate of pneumonectomies was $25.5 \%$. A 30 -day mortality rate for pneumonectomy of $5-20 \%$ has been classically reported in the literature and thus we consider it an important confounding bias. A significant morbidity rate of $27.7 \%$ has been reported in the literature. Furthermore, eight patients died between days 42 (6 weeks) and 90, a period within which first cycle of adjuvant ChT is usually administered. We think that the presence of three cases of sudden death requires additional investigation.

OS and DFS rates were similar to other comparable trials. Five-year OS was $55.7 \%$ while 5 -year DFS was $41.3 \%$. As expected, mediastinal lymph node involvement was associated with a worse prognosis. OS was $61.7 \%$, $51.5 \%$ and $42.3 \%$ for patients with $\mathrm{N} 1$ only, N2 only and $\mathrm{N} 1+\mathrm{N} 2$ disease. Five-year DFS was $41.3 \%$. Again, DFS rates decreased with lymphatic spread $(45.8 \%$ for $\mathrm{N} 1,40.1 \%$ for $\mathrm{N} 2$ and $30 \%$ for $\mathrm{N} 1+\mathrm{N} 2$ ). Interestingly, when analyzing in pairs, only the combination of $\mathrm{N} 1+\mathrm{N} 2$ involvement significantly influenced prognosis. Skip metastases were not associated with a worse prognosis. The number of mediastinal regions assessed did not affect OS, but the number of lymph nodes resected was significantly associated with a better prognosis in terms of OS and DFS. This seems to oppose our results showing that the more accurate the LND, the higher the likelihood of detecting $\mathrm{N} 1+\mathrm{N} 2$ disease (and therefore, a prediction of worse prognosis). We found that detection of $\mathrm{N}$ positive disease after resection of less than 8 lymph nodes, was associated to worse prognosis when compared to DFS of patients subjected to a more accurate lymphadenectomy, suggesting that detection of low number of $\mathrm{N}$-positive lymph nodes after a more accurate $\mathrm{LN}$-dissection (meaning higher number of lymph nodes resected) may identify a cohort of patients with better prognosis. The use of the number of tumor-positive lymph nodes resected as a prognostic factor in NSCLC patients has been previously reported $(27,28)$. The lack of a relationship between the type of resection and prognosis suggests that resection of the primary tumor is well established and was properly performed. Only 
pneumonectomy was related with better DFS rates, but with no differences on OS. Nevertheless, we should not forget that the number of lymph nodes assessed was significantly higher in pneumonectomies than in lobectomies or bilobectomies. Adenocarcinoma was associated with better outcomes than other non-small cell histological subtypes.

In conclusion, after evaluating the quality of surgical issues relating to hilar and mediastinal examination in our SCAT trial series, we found that international recommendations were not considered for the design of the trial and were not followed in a high proportion of surgical procedures. Hilar and mediastinal lymph node assessment and involvement showed to impact prognosis. Important issues for the analysis of a surgical series, such as postoperative mortality, could not be evaluated owing to trial design. Even when it comes to analyze systemic treatments, in the face of a surgical series, surgical audit of the minimum quality criteria defined by the IASLC must be followed. The role of surgeons throughout the design of trials and control of potential biases in terms of the surgical procedure itself seems essential.

\section{Acknowledgments}

A total of 47 centers participated in SLCG-SCAT trials. We appreciate the role of all surgeons involved. Besides those included as authors, we also recognize the participation of $\mathrm{R}$. Paniagua, R. Arrabal, AJ. Torres, D. Agero, C. Baamonde, JJ. Rivas, S. Quevedo, JM. Prim, J. Rodríguez, A. Sánchez Palencia, J. Moradiellos, A. Varela, F. Sebastián, M. Jiménez, R. Guijarro, A. Arnau, JA. Torrecilla, J. Gimferrer, C. Montero, AM. Gómez, J. Calatayud, N. Mañés, J. Astudillo, J. Galbis, E. Martínez, A. Carvajal, JL. Martín de Nicolás, JM. Izquierdo, L. Molins, J. Lago, I. Muguruza, Mariñán, J. Maestre, R. Rami-Porta, FJ. Belda and C. Hernández. Authors thank Medical Statistics Consulting S.L (Valencia) for proof reading and editing services.

Funding: SCAT-SLCG trial was sponsored by SanofiAventis.

\section{Footnote}

Reporting Checklist: The authors have completed the STROBE reporting checklist. Available at: http://dx.doi. org/10.21037/tlcr-20-1055

Data Sharing Statement: Available at: http://dx.doi. org/10.21037/tlcr-20-1055
Conflicts of Interest: All authors have completed the ICMJE uniform disclosure form (available at: http://dx.doi. org/10.21037/tlcr-20-1055). The authors have no conflicts of interest to declare.

Ethical Statement: The authors declare that they are all accountable for all aspects of the work (if applied, including full data access, integrity of the data and the accuracy of the data analysis) in ensuring that questions related to the accuracy or integrity of any part of the work are appropriately investigated and resolved. The study was approved by institutional/regional/national ethics/ committee/ethics board of every hospital participating in the trial (2007-000067-15) and informed consent was taken from all the patients.

Open Access Statement: This is an Open Access article distributed in accordance with the Creative Commons Attribution-NonCommercial-NoDerivs 4.0 International License (CC BY-NC-ND 4.0), which permits the noncommercial replication and distribution of the article with the strict proviso that no changes or edits are made and the original work is properly cited (including links to both the formal publication through the relevant DOI and the license). See: https://creativecommons.org/licenses/by-nc-nd/4.0/.

\section{References}

1. van Rens MT, de la Riviere AB, Elbers HR et al. Prognostic assessment of 2,361 patients who underwent pulmonary resection for non-small cell lung cancer, stage I, II, and IIIA. Chest 2000;117:374-9.

2. Burdett S, Pignon JP, Tierney J, et al. Adjuvant chemotherapy for resected early-stage non-small cell lung cancer. Cochrane Database Syst Rev 2015;(3):CD011430.

3. Chemotherapy in non-small cell lung cancer: a metaanalysis using updated data on individual patients from 52 randomised clinical trials. Non-small Cell Lung Cancer Collaborative Group. BMJ 1995;311:899-909.

4. Bradbury P, Sivajohanathan D, Chan A, et al. Postoperative Adjuvant Systemic Therapy in Completely Resected NonSmall-Cell Lung Cancer: A Systematic Review. Clin Lung Cancer 2017;18:259-273.e8.

5. Massuti B, Jimenez U, Rodriguez Paniagua M, et al. SCAT trial: Phase III Spanish customized adjuvant treatment according BRCA1 mRNA levels in stage II-IIIA non-small cell lung cancer. J Clin Oncol 2011;29:208.

6. Rami-Porta R, Kuzdzal J, Zielinski M. Complete resection in lung cancer surgery: proposed definition by R. Rami- 
Porta, C. Wittekind and P. Goldstraw. Lung Cancer 2006;51:131-2; author reply 133-4.

7. Scagliotti GV. Adjuvant and neoadjuvant chemotherapy for early-stage nonsmall cell lung cancer. In: B. D. Pass HI, Scagliotti GV. editors. IASLC Thoracic Oncology. 2nd ed. Philadelphia: Elsevier; 2018:512-24.

8. Winton T, Livingston R, Johnson D, et al. Vinorelbine plus cisplatin vs. observation in resected non-small-cell lung cancer. N Engl J Med 2005;352:2589-97.

9. Pignon JP, Tribodet H, Scagliotti GV, et al. Lung adjuvant cisplatin evaluation: a pooled analysis by the LACE Collaborative Group. J Clin Oncol 2008;26:3552-9.

10. Varlotto JM, Recht A, Nikolov M, et al. Extent of lymphadenectomy and outcome for patients with stage I nonsmall cell lung cancer. Cancer 2009;115:851-8.

11. Osarogiagbon RU, Allen JW, Farooq A, et al. Objective review of mediastinal lymph node examination in a lung cancer resection cohort. J Thorac Oncol 2012;7:390-6.

12. Osarogiagbon RU, Yu X. Nonexamination of lymph nodes and survival after resection of non-small cell lung cancer. Ann Thorac Surg 2013;96:1178-89.

13. Osarogiagbon RU, Ray MA, Faris NR, et al. Prognostic Value of National Comprehensive Cancer Network Lung Cancer Resection Quality Criteria. Ann Thorac Surg 2017;103:1557-65.

14. Osarogiagbon RU, Ogbata O, Yu X. Number of lymph nodes associated with maximal reduction of long-term mortality risk in pathologic node-negative non-small cell lung cancer. Ann Thorac Surg 2014;97:385-93.

15. Becker DJ, Levy BP, Gold HT, et al. Influence of Extent of Lymph Node Evaluation on Survival for Pathologically Lymph Node Negative Non-Small Cell Lung Cancer. Am J Clin Oncol 2018;41:820-5.

16. Legras A, Mordant P, Arame A, et al. Long-term survival of patients with $\mathrm{pN} 2$ lung cancer according to the pattern of lymphatic spread. Ann Thorac Surg 2014;97:1156-62.

17. Zheng H, Wang LM, Bao F, et al. Re-appraisal of N2 disease by lymphatic drainage pattern for non-small-cell lung cancers: by terms of nodal stations, zones, chains, and a composite. Lung Cancer 2011;74:497-503.

18. Yoo C, Yoon S, Lee DH, et al. Prognostic Significance of the Number of Metastatic pN2 Lymph Nodes in Stage IIIA-N2 Non-Small-Cell Lung Cancer After Curative Resection. Clin Lung Cancer 2015;16:e203-12.

19. Smeltzer MP, Faris NR, Ray MA, et al. Association of Pathologic Nodal Staging Quality With Survival Among Patients With Non-Small Cell Lung Cancer After Resection With Curative Intent. JAMA Oncol 2018;4:80-7.

20. Yazgan S, Ucvet A, Gursoy S, et al. Single-station skip-N2 disease: good prognosis in resected non-small-cell lung cancer (long-term results in skip-N2 disease). Interact Cardiovasc Thorac Surg 2019;28:247-52.

21. Asamura H, Chansky K, Crowley J, et al. The International Association for the Study of Lung Cancer Lung Cancer Staging Project: Proposals for the Revision of the N Descriptors in the Forthcoming 8th Edition of the TNM Classification for Lung Cancer. J Thorac Oncol 2015;10:1675-84.

22. Wang X, Yan S, Lv C, et al. Impact of Omission of Intrapulmonary Lymph Node Retrieval on Outcome Evaluation of Lung Cancer Patients Without Lymph Node Metastasis: A Propensity Score Matching Analysis. Clin Lung Cancer 2017;18:e411-e416.

23. Nomori H, Ohba Y, Shibata H, et al. Required area of lymph node sampling during segmentectomy for clinical stage IA non-small cell lung cancer. J Thorac Cardiovasc Surg 2010;139:38-42.

24. Gagliasso M, Migliaretti G and Ardissone F. Assessing the prognostic impact of the International Association for the Study of Lung Cancer proposed definitions of complete, uncertain, and incomplete resection in non-small cell lung cancer surgery. Lung Cancer 2017;111:124-30.

25. Liang RB, Yang J, Zeng TS, et al. Incidence and Distribution of Lobe-Specific Mediastinal Lymph Node Metastasis in Non-small Cell Lung Cancer: Data from 4511 Resected Cases. Ann Surg Oncol 2018;25:3300-7.

26. Ray MA, Faris NR, Smeltzer MP, et al. Effectiveness of Implemented Interventions on Pathologic Nodal Staging of Non-Small Cell Lung Cancer. Ann Thorac Surg 2018;106:228-34.

27. Matsuguma H, Oki I, Nakahara R, et al. Proposal of new nodal classifications for non-small-cell lung cancer based on the number and ratio of metastatic lymph nodes. Eur J Cardiothorac Surg 2012;41:19-24.

28. Qiu C, Dong W, Su B, et al. The prognostic value of ratiobased lymph node staging in resected non-small-cell lung cancer. J Thorac Oncol 2013;8:429-35.

Cite this article as: Jarabo Sarceda JR, Bolufer Nadal S, Mongil Poce R, López de Castro P, Moreno Balsalobre R, Peñalver Cuesta JC, Embún Flor R, Pac Ferrer J, Algar Algar FJ, Gámez García AP, Jiménez MF, Sales-Badía JG, Pereira E, Massuti B, Provencio M, Hernando Trancho F. Spanish Lung Cancer Group SCAT trial: surgical audit to lymph node assessment based on IASLC recommendations. Transl Lung Cancer Res 2021;10(4):1761-1772. doi: 10.21037/tlcr-20-1055 